\title{
Synthesis and Characterisation of Polymeric Nanofibers Poly (vinyl alcohol) and Poly (vinyl alcohol)/Silica Using Indigenous Electrospinning Set Up
}

\author{
K. Sasipriya, R. Suriyaprabha, P. Prabu, V. Rajendran* \\ Centre for Nanoscience and Technology, K. S. Rangasamy College of Technology, \\ Tiruchengode - 637 215, Tamil Nadu, India
}

Received: September 7, 2011; Revised: January 3, 2013

\begin{abstract}
Indigenous design and fabrication horizontal of electrospinning set up was developed to facilitate with double drum conveyor belt system to make ease in harvesting nanofibers rapidly. As a bench mark study, organic-inorganic nanofiber composite was synthesised employing our indigenous electrospinning set up. The aqueous solution of poly (vinyl alcohol) and poly (vinyl alcohol)/silica sol were employed to produce nanofiber mats in order to vary the experimental parameters such as voltage, solvent effect and the effect of catalyst. The synthesised pure electro spun poly (vinyl alcohol) and poly (vinyl alcohol)/silica sol fibers were characterized by Scanning electron microscopy (SEM), Atomic force microscopy (AFM) and Fourier transform infra red spectroscopy (FTIR). According to the results, the fine polymeric nanofibers were achieved in the size range of 100-500 nm for pure poly (vinyl alcohol) fiber and 100-700 $\mathrm{nm}$ for polyvinyl alcohol/silica and the constitution of silica in rendering better fiber mats with this double drum set up.
\end{abstract}

Keywords: electrospinning, double drum, $\mathrm{PVA} / \mathrm{SiO}_{2}$ composite, nanofiber mats

\section{Introduction}

The recent developments in nanofiber technology provides an unique opportunity to create revolutionary polymeric inorganic nanocomposites with appropriate characteristics which can be applied for various non medical and medical applications such as textile applications, optical devices, membranes, sensors, tissue engineering scaffold, catalytic nanofibers etc ${ }^{1}$. Nanofibers have been extensively studied because of their extraordinary properties such as light weight and large surface area to volume ratio. Many potential applications for nanofibers have been proposed, including sensors, nanocomposites, biomaterials, filtrations, device wipes, electrical applications and also wound dressings material ${ }^{2,3}$.

Attractive features of electrospinning are the simple and cost effective experimental set up. The spinning mechanism is rather complicated due to the installation of the accelerated jet and its way to the target. It contains three basic components such as syringe pump, high voltage supply and a collector. Electrospinning itself possesses higher flexibility and versatility in higher modification ${ }^{4}$. By this technique, organic/inorganic composite fibers with desired ratios can be fabricated. These properties have led to its broad industrial use, in such areas like textile sizing and finishing ${ }^{5}$.

Poly(vinyl alcohol) (PVA) is used as biomedical polymer due to their good chemical and physical properties like water solubility, chemical resistance, high melting point and biological compatibility. In addition, it is an inexpensive, non-toxic material having high tensile strength and flexibility offering the possibility of functionalisation due to its pendant hydroxyl groups. Electrospinning of

*e-mail: veerajendran@gmail.com
PVA can be performed from aqueous solutions leading to generation of homogenous nanofiber webs ${ }^{6}$. Chemical cross linking of the PVA nanofibers presents an adequate way for stabilization of the fiber towards aqueous surroundings beneath physical cross linking processes ${ }^{1}$. Synthesis of electrospun PVA fibers for its morphological characteristics and size, the relationship among various process parameters, concentration of fibers obtained from electrospinning have been well studied in PVA. When compare to pure PVA nanofibers, $\mathrm{PVA} / \mathrm{SiO}_{2}$ has higher water solubility and thermal stability ${ }^{7}$.

Under specific process conditions, electrospinning can produce fine polymeric nanofibers of organic/inorganic composite from $\mathrm{PVA} / \mathrm{SiO}_{2}$, solution. But these fine polymeric nanofibers can be achieved only through the designing of electrospinning set up for optimized polymeric fiber production at large scale.

At present, a broad spectrum of materials ranging from a variety of natural or synthetic polymer composites, semiconductors and ceramics were successfully electrospun into nanoscaled fibers ${ }^{8,9}$, whereas the process itself has been the subject of investigation for scale-up purposes. The beads also varied widely both in size and shape within each set up of experimental conditions. Their shape ranged from spherical, globular, elongated and their dimension spanned from 170-1500 $\mathrm{nm}^{10}$. To our reference, the synthesis of these composite based nanofibers via electrospinning was performed using water and ortho phosphoric acid as a solvent and catalyst respectively ${ }^{11}$. But the fidelity and productivity can only be enhanced through improving of electrospinning process parameters and the preparative method of $\mathrm{PVA} / \mathrm{SiO}_{2}$ fiber composites as followed in sol preparation. Hence, 
there is a need for the effective electrospinning set up to synthesise such nanofiber composites uniform and rapid at large scale level.

In this study, we set an electrospinning set up for the production of fiber mats of $\mathrm{PVA} / \mathrm{SiO}_{2}$ composites with our indigenously designed experimental set up and optimizing its process parameters, investigation and its characteristics which would enable us to find the advantages over various industrial applications such as biomedical and textiles.

\section{Material and Method}

\subsection{Materials}

Poly (vinyl alcohol) (MW approx. 1,25,000, Loba, LR), Tetra ethyl orthosilicate (TEOS, MW approx. 208.33, Sigma Aldrich), Ethanol (99.9\% purity) and Ammonia solution (min. 25\%, Merck GR), ultra pure water (Sartorius AG, Arium 611UF, Germany)

\subsection{Designing of indigenous electrospinning set up}

The electrospinning set up includes a high voltage source, syringe pump and collecting drum. The set up was designed horizontally with a provision to vary the applied voltage from 10 to $50 \mathrm{kV}$ using high voltage power supply. The flow rate of solution was controlled using the syringe pump. The designed collecting drum is unique in this set up i.e., two different drum with different diameter, connected with conveyor belt in order to collect fibers uniform and rapid at large scale samples.

\subsection{Preparation of $\mathrm{PVA}$ and $\mathrm{PVA} / \mathrm{SiO}_{2}$ spinning solution}

Preparation of PVA and PVA/silica sol were prepared by varying their composition ratio vary in their ratios and composition. Aqueous PVA solution was prepared by dissolving $5 \mathrm{~g}$ of commercially available poly (vinyl alcohol) in distilled water and stirred for $3 \mathrm{~h}$ at $333 \mathrm{~K}$. This process was continued until the formation of viscous solution. Then, the silica sol was prepared from tetra ethyl orthosilicate ethanol and ammonia. Here, ammonia was used as a catalyst instead of nitric acid and ethanol as a solvent for the sol gel synthesis of silica. $2 \mathrm{~mL}$ of TEOS was dissolved in $15 \mathrm{~mL}$ of ethanol and then stirred for $10 \mathrm{~min}$. The hydrolysis and conduction were carried out by the drop wise addition of ammonia solution to TEOS with vigorous stirring at room temperature for $3 \mathrm{~h}$ to get white transparent silica sol. Then, it was added drop wise into 5\% aqueous solution of PVA. It was stirred until viscous solution of $\mathrm{PVA} / \mathrm{SiO}_{2}$ composite formed.

\subsection{Preparation of fiber/fiber composites}

PVA and PVA/SiO $\mathrm{S}_{2}$ spinning solutions were separately taken in glass syringe with a stainless steel needle. The positive terminal of the high voltage power supply is connected to the end of the capillary while the negative terminal is connected to the collecting drum, covered with an aluminum foil. Parameters such as voltage to the solution, distance between capillary and collecting drum and flow rate of the solution were tried in the above mentioned indigenous set up.

\subsection{Characterization}

The synthesized polymeric nanofibers namely PVA and $\mathrm{PVA} / \mathrm{SiO}_{2}$ were characterised. The formation of nanofibers is observed using Atomic force microscopy (Innova, Veeco, USA). The presence of PVA and PVA/SiO nanofibers were analyzed for its surface morphology using Scanning electron microscopy (JEOL JSM-6390LV, Japan) and Fourier Transform infrared spectra was obtained employing the FTIR spectrometer (Thermo electron corporation, Nexus 670, USA) in the wave number region of $4000-400 \mathrm{~cm}^{-1}$ to obtain the characteristic peaks of PVA and $\mathrm{PVA} / \mathrm{SiO}_{2}$.

\section{Results and Discussion}

As a consequence of the strong interaction between the inorganic and the organic phase, the spinning behaviour and the morphology of the hybrid fibers differ significantly from that of pure silica respectively. Usually, the generated fibers possess limited lengths and the thickness of the deposited fiber layer is low. These limitations can be overcome by this unique set up. Development of $\mathrm{PVA} / \mathrm{SiO}_{2}$ polymeric nanofiber composites by incorporation of the solution compounding and self assembly techniques are proposed with electrospinning set up (Figure 1). The synthesized

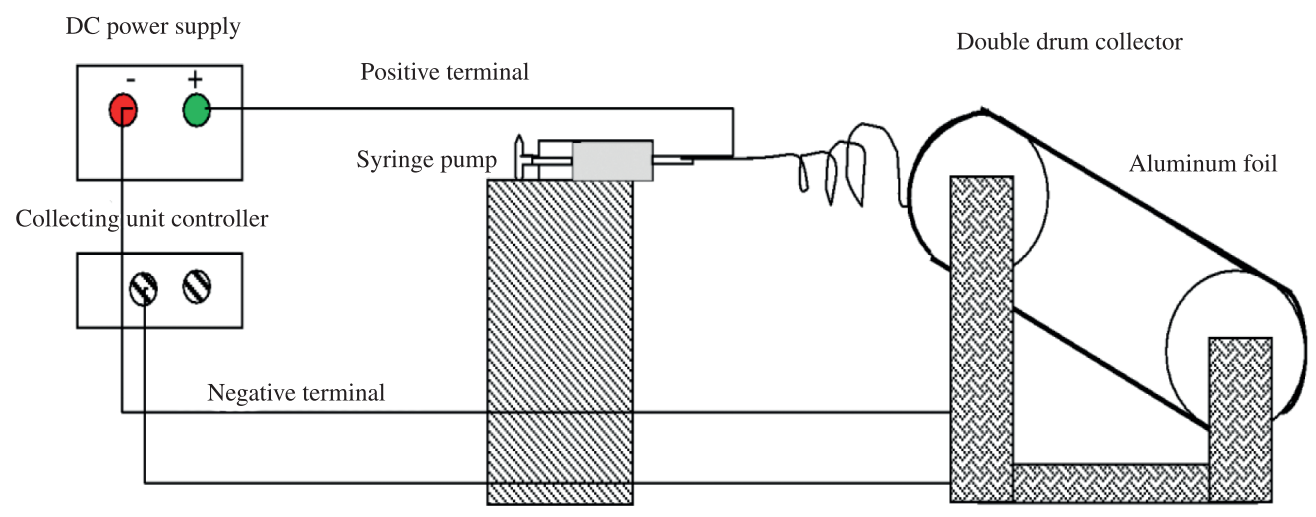

Figure 1. A block diagram of an indigenously designed electrospinning set up. 
nanofibers have been collected in an appropriate size through double drum conveyor belt system. Different process parameters such as voltage supply, flow rate and volume of solution were optimized in the present study. A better collection of nanofibers and thereby applying a high voltage to the solution, a dense web of fibers can be collected on the aluminium foil at $30 \mathrm{kV}$ which was found to be dense and the distance between capillary and collecting drum also optimized as $12 \mathrm{~cm}$ and flow rate $1 \mathrm{~mL} / \mathrm{min}$ for spinning. The obtained nanofibers are characterized through various art techniques. Solvent and catalyst effect also play a major role in the formation of defect free fibers in the nanometer range. In this study, both are found better to produce fine fibers, less aggregation of silica on PVA matrix and requires low content of PVA for fine fibers production when compared to other preparative method ${ }^{11}$.

Surface morphology and diameters of the electrospun fibers are examined using scanning electron microscopy (Figure 2). Figure 2a represents the SEM images of

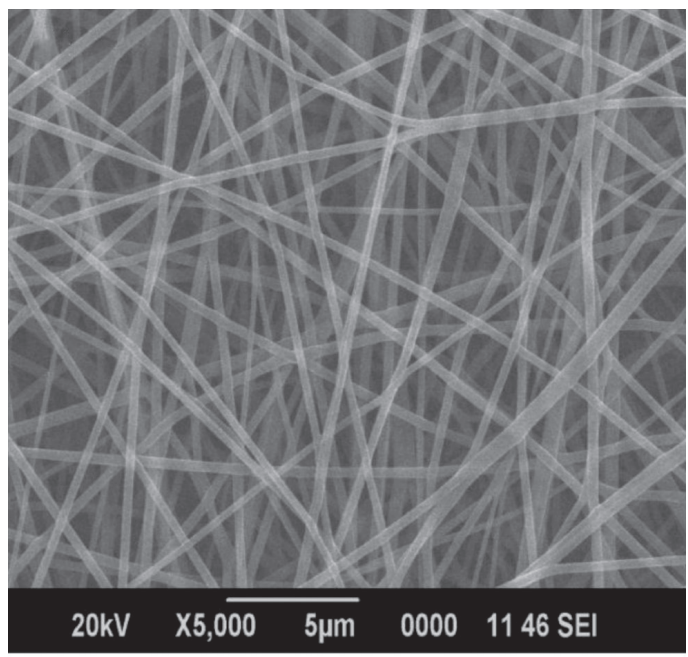

(a)

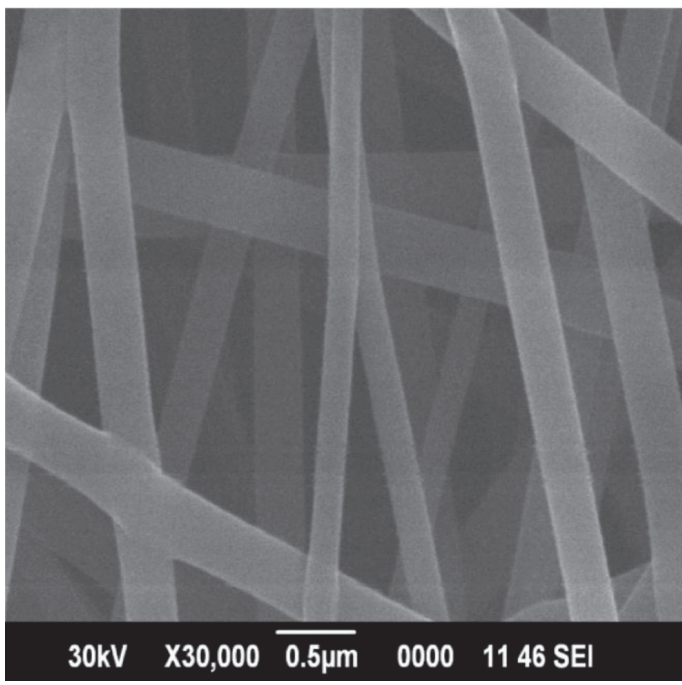

(b)

Figure 2. Scanning electron micrograph of electrospun PVA nano fibers at different magnifications $(5 \mu \mathrm{m}$ and $0.5 \mu \mathrm{m})$.
PVA electrospun nanofibers scanned at $5 \mu \mathrm{m}$ and $0.5 \mu \mathrm{m}$ magnifications respectively. The PVA solution produces a random distribution of fine fibers at an average diameter range of $500 \mathrm{~nm}$ with smooth surface. $\mathrm{PVA} / \mathrm{SiO}_{2}$ fibers are observed as discrete, fine fibers smaller than pure PVA fibers, as shown in Figure 3. The average fiber diameter of $\mathrm{PVA} / \mathrm{SiO}_{2}$ is $100-500 \mathrm{~nm}$. Functionalised nanofibers can be fabricated by this optimized electrospinning set up with high voltage electric field from polymer solution. The formations of beads are widely observed between the electrospun fibers prepared with this concentration of solution and with different process parameters. The viscosity, net charge density and surface tension of solution are some of the key parameters to obtain bead fibers with different fiber morphologies. Similar process parameters paved a way to synthesize functionalised PVA/Silica nanofibers at 5\% PVA concentration which are clearly shown in AFM images.

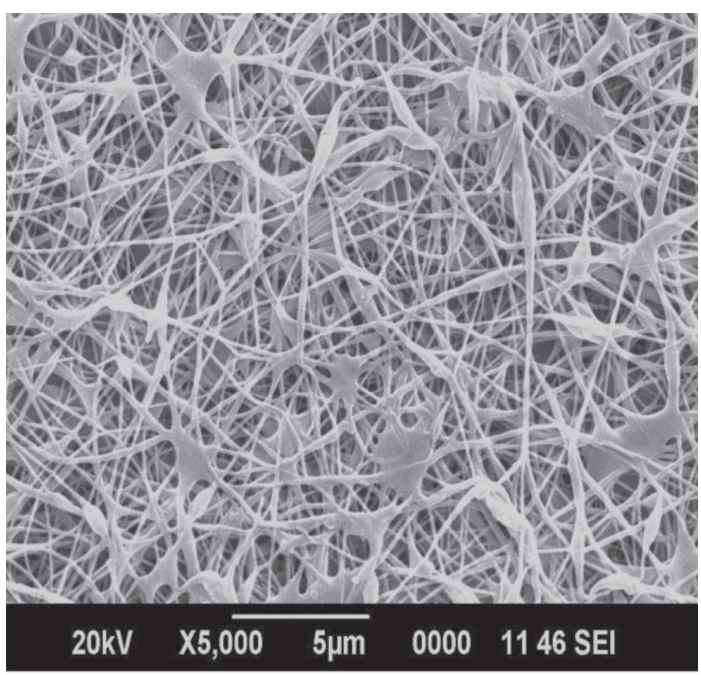

(a)

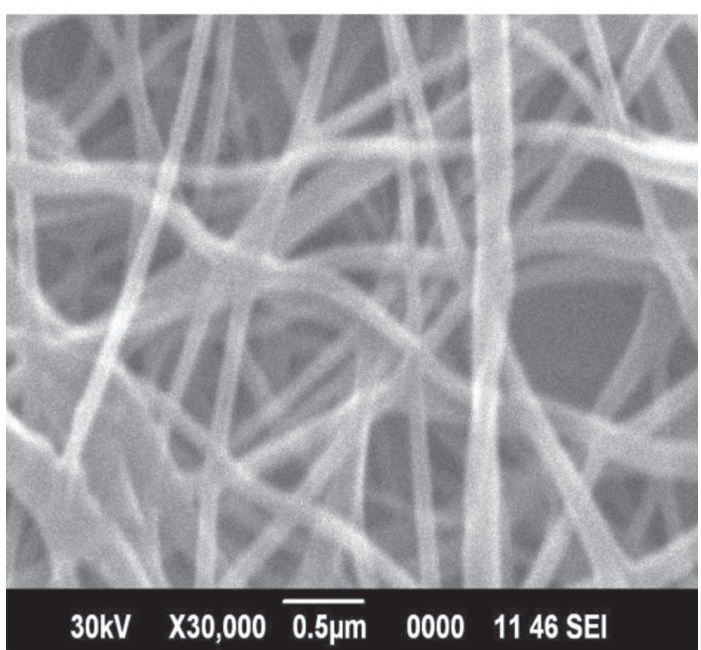

(b)

Figure 3. Scanning electron micrograph of electrospun $\mathrm{PVA} / \mathrm{SiO}_{2}$ nano fibers at different magnifications $(5 \mu \mathrm{m}$ and $0.5 \mu \mathrm{m})$. 
AFM image of electrospun PVA non - woven mat is shown in Figure 4 which supports the above discussion. Figures $4 \mathrm{a}$ and $\mathrm{b}$ show the 2D image of electro spun fiber in scan area $50 \times 50 \mu \mathrm{m}$ and $20 \times 20 \mu \mathrm{m}$, which allow in identifying the morphological regularities of nanofibers. Figure $4 \mathrm{c}$ shows the cursor plot obtained for the line A - B, in which the fibers from $0.0392 \mu \mathrm{m}$ to $0.147 \mu \mathrm{m}$ in height are measured in a single scan. Figure 5 shows the AFM images of $\mathrm{PVA} / \mathrm{SiO}_{2}$ which reveal that the fibers have diameters varying from $100 \mathrm{~nm}$ to $700 \mathrm{~nm}$. From the 2D image (Figure 5), it is evident that the beads in the fibers are visible at these process parameters. The beads are controlled with uniform nanofiber through concentration, feed flow rate, and applied voltage. Figure $5 \mathrm{~b}$ shows the cursor plot obtained for the line $\mathrm{A}-\mathrm{B}$, in which the fibers from $0.0421 \mu \mathrm{m}$ to $0.0064 \mu \mathrm{m}$ in height are measured. When increased percentage of silica added into PVA/SiO $\mathrm{Sim}_{2}$ composites can be clearly observed in PVA matrix. The surface of the $\mathrm{SiO}_{2}$ at the edges appears brighter and this implies aggregation of $\mathrm{SiO}_{2}$ in the solution greatly be reduced and uniform mixing was achieved ${ }^{12}$. Less percentage of silica in PVA matrix reduces the property of aggregation tendency because of the problem of overload. The surface roughness of nanocomposites is very less in $5 \%$ $\mathrm{PVA} / \mathrm{SiO}_{2}$ matrix. The maximum peak to valley height of

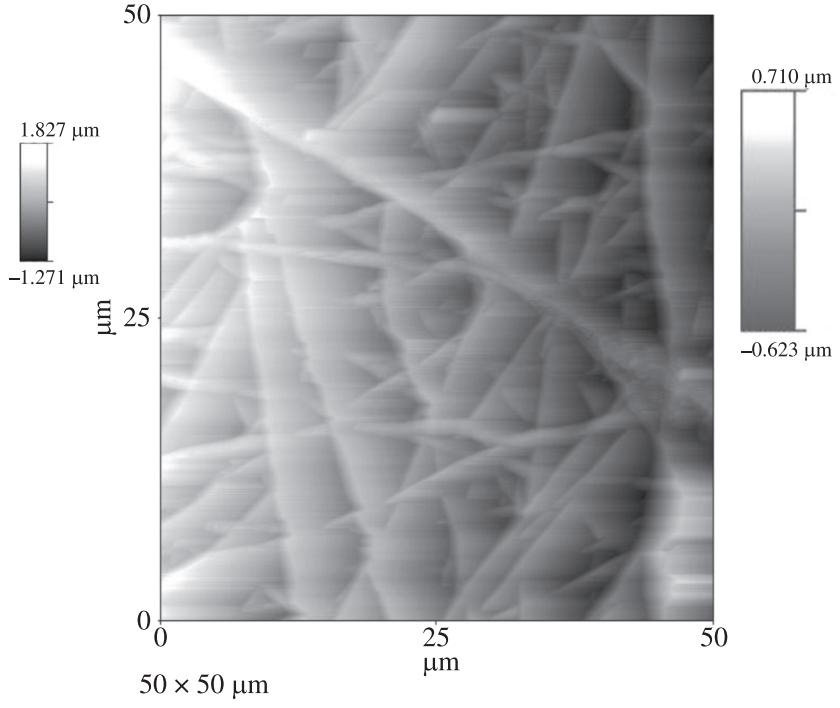

(a)

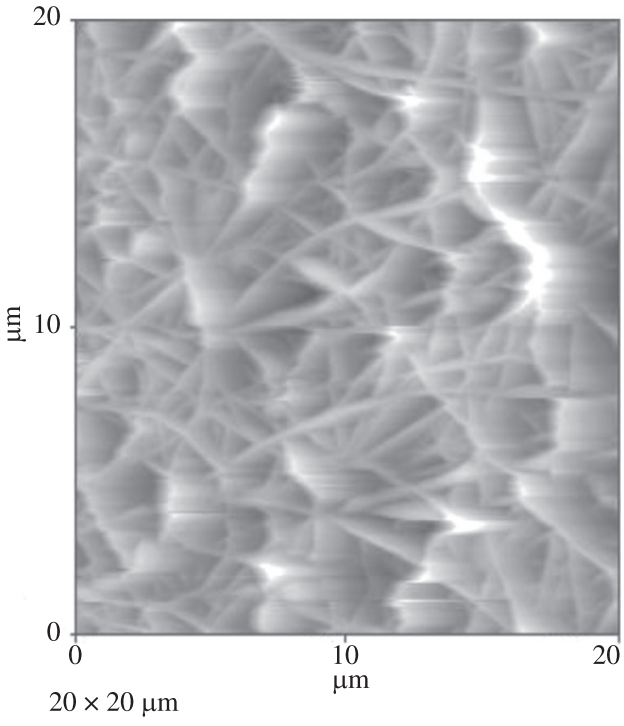

(b)
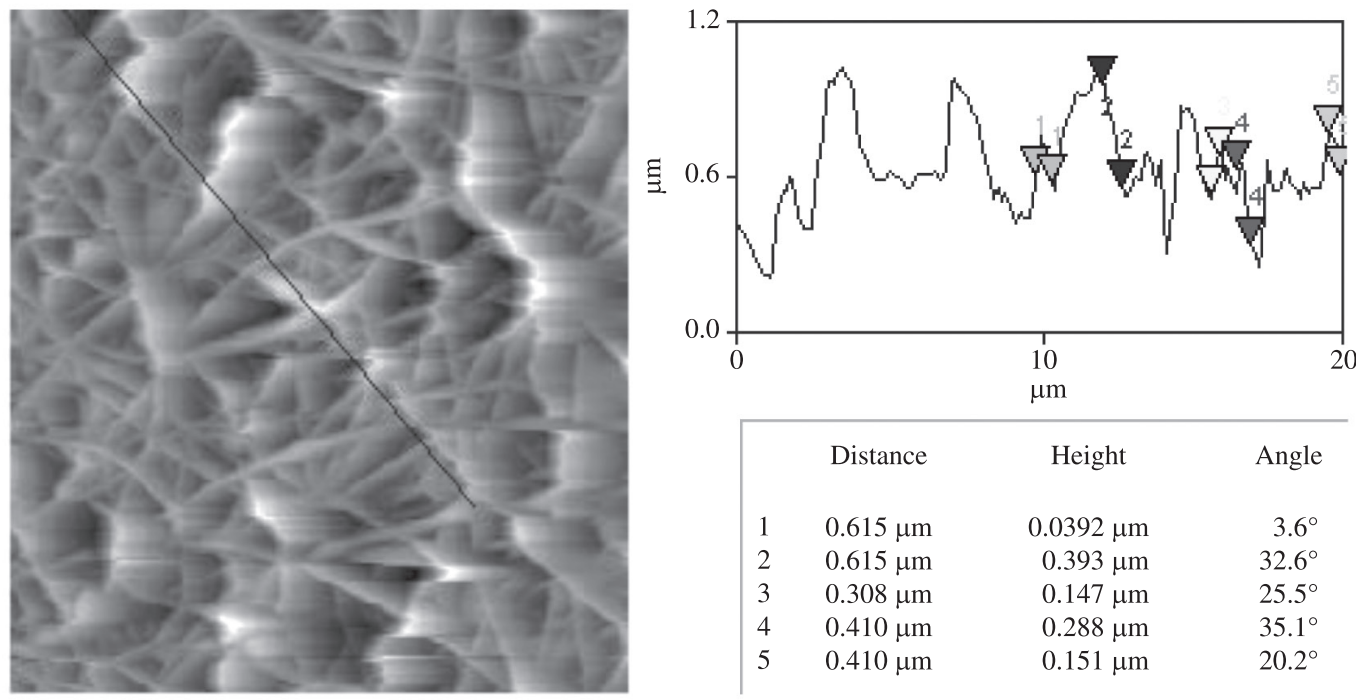

\begin{tabular}{|ccrr}
\hline & Distance & \multicolumn{1}{c}{ Height } & Angle \\
& & & \\
1 & $0.615 \mu \mathrm{m}$ & $0.0392 \mu \mathrm{m}$ & $3.6^{\circ}$ \\
2 & $0.615 \mu \mathrm{m}$ & $0.393 \mu \mathrm{m}$ & $32.6^{\circ}$ \\
3 & $0.308 \mu \mathrm{m}$ & $0.147 \mu \mathrm{m}$ & $25.5^{\circ}$ \\
4 & $0.410 \mu \mathrm{m}$ & $0.288 \mu \mathrm{m}$ & $35.1^{\circ}$ \\
5 & $0.410 \mu \mathrm{m}$ & $0.151 \mu \mathrm{m}$ & $20.2^{\circ}$
\end{tabular}

(c)

Figure 4. AFM images of electrospun PVA fibers. 
the pure PVA is about $39 \mathrm{~nm}$ and showing smooth surface which indicate that it is having smooth fibers. In $\mathrm{PVA} / \mathrm{SiO}_{2}$ composites, the formation of fibers showed smooth and smaller in size of nanofibers that is around 100-700 nm which coordinates with previous reports ${ }^{12}$. Results give smooth surface when compare to pure PVA fibers. This is because that $\mathrm{PVA} / \mathrm{SiO}_{2}$ nanofibers influence of low $\mathrm{SiO}_{2}$ content in a sample and higher uniformity in dispersion of $\mathrm{SiO}_{2}$ in PVA results in good elongation of fibers and also to smooth surfaces.

In addition, FTIR spectrum of PVA nanofiber is shown in Figure 6. The basic composition of PVA is $-\left(\mathrm{CH}_{2}-\mathrm{CHOH}\right)_{n}$ and the monomer structure is $\left(\mathrm{CH}_{2}=\mathrm{CHOH}\right)$. Figure 6 clearly reveals the major peaks associated with PVA. The peak observed at approximately $1100 \mathrm{~cm}^{-1}$ is attributed to the presence of terminal poly vinyl groups and $1735 \mathrm{~cm}^{-1}$ indicates the $-\mathrm{C}=\mathrm{O}$ carbonyl stretching bond. It is observed that the band obtained at 2850-3000 $\mathrm{cm}^{-1}$ indicates $\mathrm{C}-\mathrm{H}$ stretching bond and the peak at $3200-3570 \mathrm{~cm}^{-1}$ is hydrogen bonded $-\mathrm{OH}$ group. The FTIR spectra of PVA/silica fibers are recorded in the spectral range of $4000-600 \mathrm{~cm}^{-1}$ as shown in Figure 7. The bond obtained near $1000 \mathrm{~cm}^{-1}$ are due to vibrations

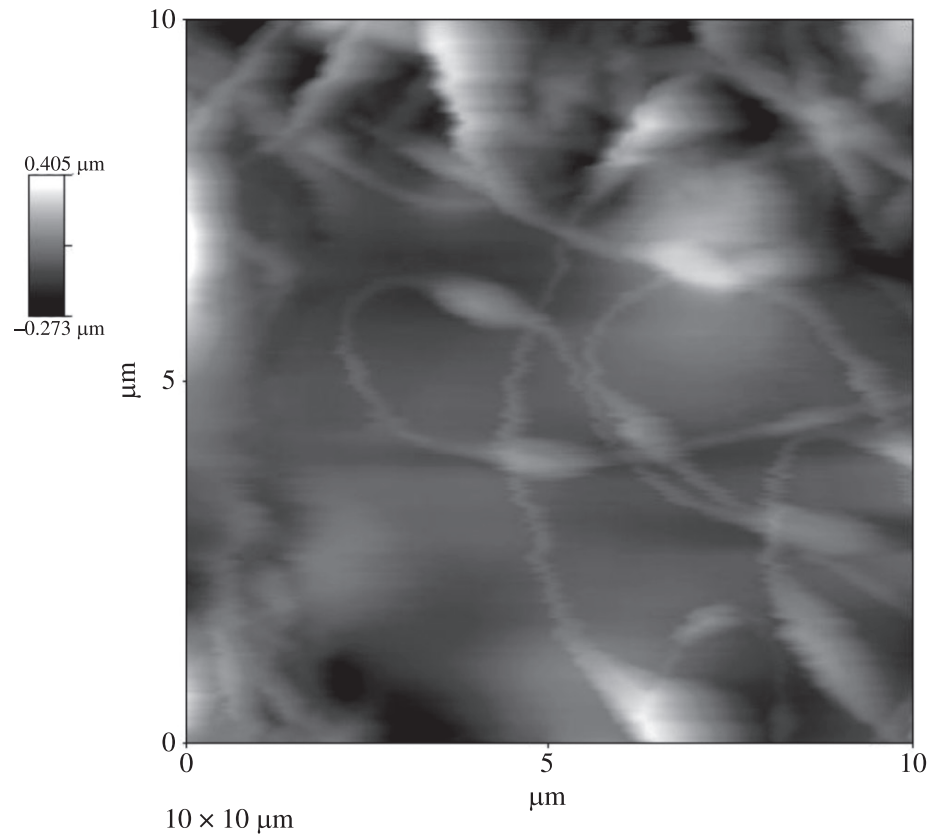

(a)
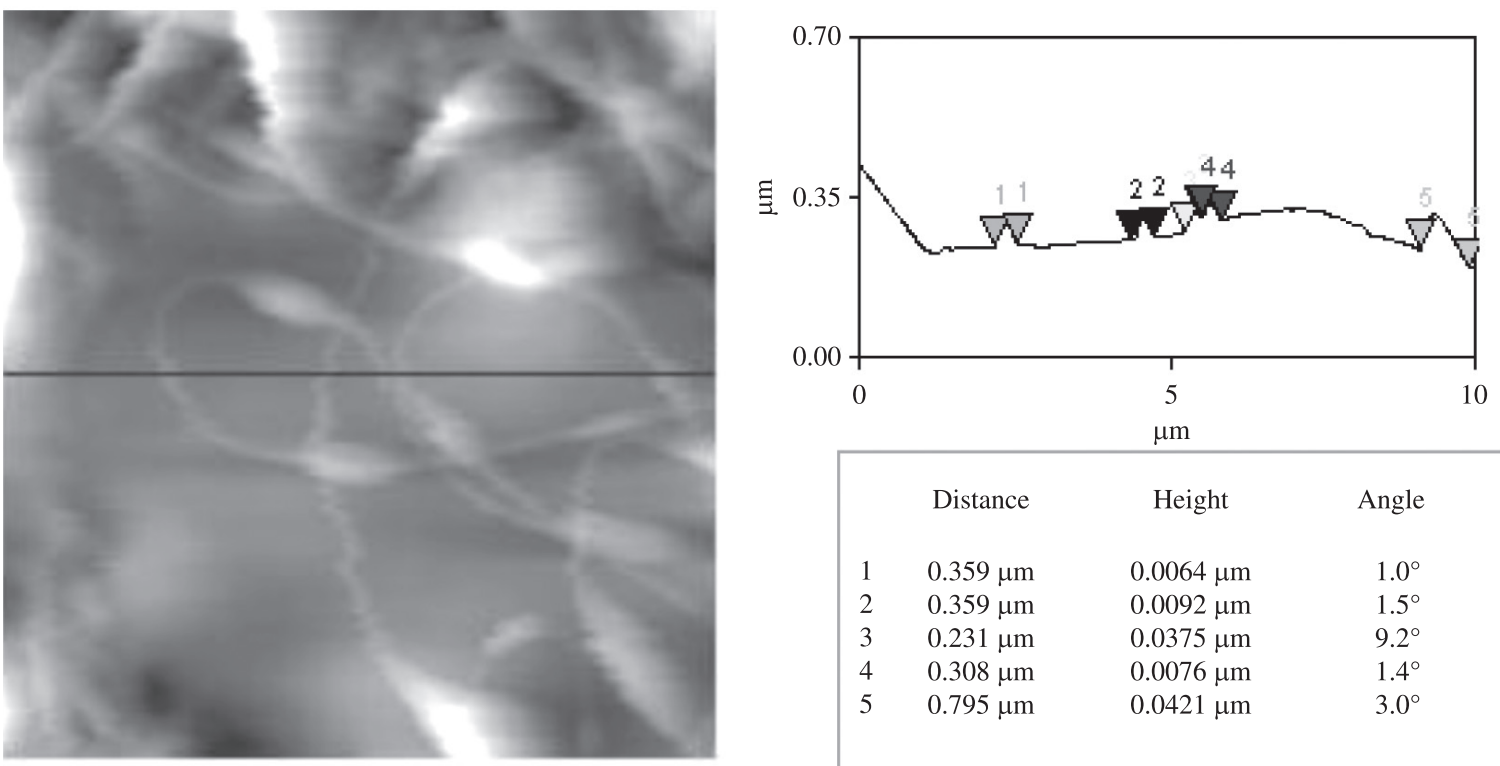

\begin{tabular}{|cccc|}
\hline & Distance & Height & Angle \\
& & & \\
1 & $0.359 \mu \mathrm{m}$ & $0.0064 \mu \mathrm{m}$ & $1.0^{\circ}$ \\
2 & $0.359 \mu \mathrm{m}$ & $0.0092 \mu \mathrm{m}$ & $1.5^{\circ}$ \\
3 & $0.231 \mu \mathrm{m}$ & $0.0375 \mu \mathrm{m}$ & $9.2^{\circ}$ \\
4 & $0.308 \mu \mathrm{m}$ & $0.0076 \mu \mathrm{m}$ & $1.4^{\circ}$ \\
5 & $0.795 \mu \mathrm{m}$ & $0.0421 \mu \mathrm{m}$ & $3.0^{\circ}$
\end{tabular}

(b)

Figure 5. AFM images of electrospun $\mathrm{PVA} / \mathrm{SiO}_{2}$ - non woven mat. 


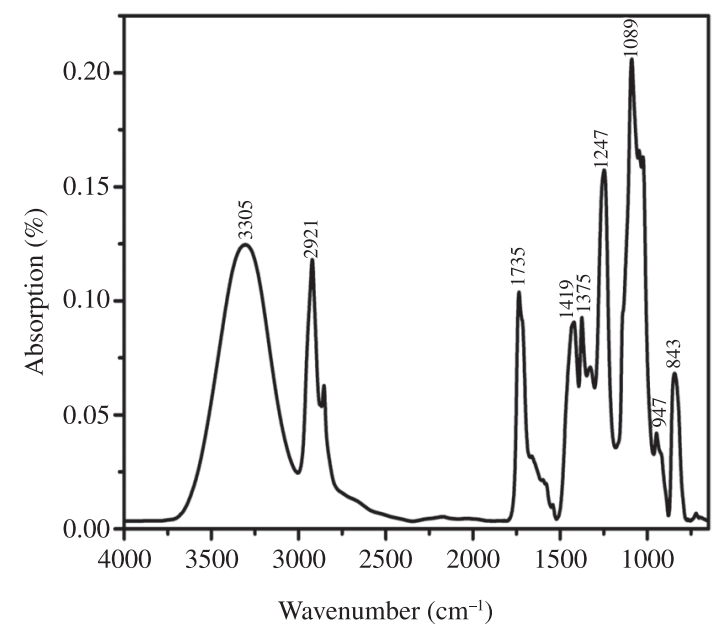

Figure 6. FTIR spectra of electrospun PVA fibers.

of $\mathrm{Si}-\mathrm{O}$ and $\mathrm{Si}-\mathrm{O}-\mathrm{Si}$ asymmetry stretching and show a broad absorption of hydrogen bonded silanols. The bond observed between 2850 and $3000 \mathrm{~cm}^{-1}$ indicates $\mathrm{C}-\mathrm{H}$ stretching bond. The broad band noticed near $3350 \mathrm{~cm}^{-1}$ is due to stretching vibrations involving the hydroxyl groups of PVA and $\mathrm{Si}-\mathrm{OH}^{13,14}$.

Combination of PVA with an inorganic sol consisting of silica results in an interlinked hybrid system due to strong interactions between the hydroxyl groups of the PVA and the residual silanol groups of the inorganic phase in form of hydrogen bonds. The network between PVA and silica suppresses the swelling of PVA in water and enhances its thermal stability ${ }^{15}$. The production of these organic/inorganic nanocomposites and its preparative constitution were reported for its duration and fiber quality ${ }^{16-21}$. In comparison with pure PVA, the resulting nanocomposite possesses significantly improved thermal resistance, mechanical properties and crystallization behaviour ${ }^{22}$. The spinning process and the morphology of the hybrid fibers differ significantly between pure PVA and PVA/silica due to the strong interaction between the inorganic and the organic phase. Hence, the PVA/silica hybrid generally tends towards the formation of beads and reflection in SEM image within the fibers. These reports might be relevant to our studies that these polymeric nanofibers have better physical properties than pure PVA especially with indigenous electrospinning system and would be more applicable in biomedical engineering and textile applications. The process parameters

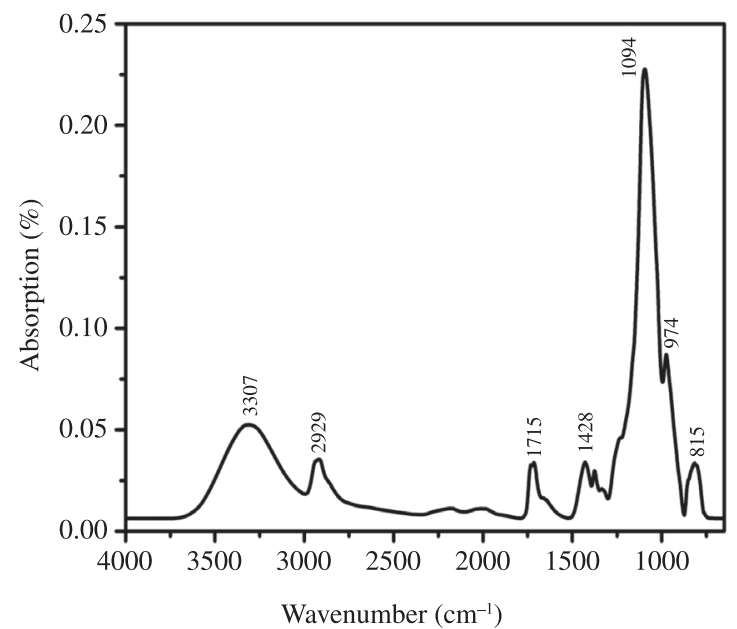

Figure 7. FTIR spectra of electrospun $\mathrm{PVA} / \mathrm{SiO}_{2}-$ non woven mat.

of indigenous electrospinning set up was optimized using voltage of $30 \mathrm{kV}$, distance of $12 \mathrm{~cm}$ from capillary and

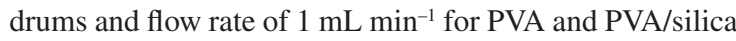
fibers production.

\section{Conclusions}

Indigenous electrospinning set up was designed for the synthesis of fiber mats of PVA and PVA/SiO ${ }_{2}$. Fibers were synthesized by optimizing electrospinning process parameters. A better collection of nanofibers collected on the aluminum foil at $30 \mathrm{kV}$ was found to be dense and the distance between capillary and collecting drum also optimized as $12 \mathrm{~cm}$ and flow rate of $1 \mathrm{~mL} / \mathrm{min}$ for spinning. These comparative studies of polymeric nanofiber mats with silica sol under different solvent and catalyst would provide to understand the special properties of organic/inorganic composite materials and also the influence of electrospinning parameters. This study paves us to imply for tissue engineering applications as well as textile application with good physical properties of polymeric nanofibers.

\section{Acknowledgements}

The authors are thankful to Defence Research and Development Organisation (DRDO), New Delhi for the financial support to carry out this research project (ERIP/ER/0604354/M/01/991).

\section{References}

1. Voigt W, Thomas H, Heine E and Moller M. Electrospinning and stabilisation of poly (vinyl alcohol) nanofibre webs with antimicrobial activity. In: Anandjiwala R, Hunter L, Kozlowski $\mathrm{R}$ and Zaikov G, editors. Textiles for Sustainable Development. New York: Nova Publishers; 2007. p. 373-384.
2. Huang L, Nagapudi K, Apkarian RP and Chaikaf EI. Engineered collagan-PEO nanofinbers and fabrics. Journal of Biomaterials Science Polymer. 2001; E1.2:979-993.

3. Jian F, Hai Tao, Tong NL and Yun-Gai W. Applications of electrospun nanofibers. Chinese Science Bulletin. 2008; 53:2265-2286. http://dx.doi.org/10.1007/ s11434-008-0319-0 
4. Teo WE and Ramakrishna S. A review on electrospinning design and nanofibre assemblies. Nanotechnology. 2006; 17:R89-106. PMid:19661572. http://dx.doi.org/10.1088/0957-4484/17/14/ R01

5. Levine M, Ikka G and Weiss P. Relation of the critical surface tension of polymers to adhesion. Journal of Polymer Science Part B: Polymer Physics. 1964; 2(9):915-919. http://dx.doi. org/10.1002/pol.1964.110020918

6. Supaphol P and Chuangchote S. On: The electrospinning of poly (vinyl alcohol) nanofiber mats: a revisit. Journal of Applied Polymer Science. 2008; 108(2):969-978. http://dx.doi. org/10.1002/app.27664

7. Ding B, Kim HY, Lee SC, Shao CC, Lee DD, Park SJ et al. Preparation and characterization of a nanoscale PVA fibers aggregate produced by electro spinning method. Journal of Polymer Science Part B: Polymer Physics. 2002; 40 (13):12611268. http://dx.doi.org/10.1002/polb.10191

8. Huang Z-M, Zhang Y-Z, Kotaki M and Ramakrishna S. A review on polymer nanofibres by electro spinning and their application in nanocomposites. Composites Science and Technology. 2003; 63:2223-2253. http://dx.doi.org/10.1016/ S0266-3538(03)00178-7

9. Sigmund W, Yuh J, Park H, Maneeratana V, Pyrgiotakis G, Daga A et al. Processing and structure relationships in electrospinning of ceramic fiber systems. Journal of American Ceramic Society. 2006; 89(2):395-407. http://dx.doi. org/10.1111/j.1551-2916.2005.00807.x

10. David YL, Michael A, Richard JA, Vohden Junior D, Chen and David CM. Tailored nanofiber morphologies using modulated electrospinning for biomedical applications. Material Research Society Symposium Proceedings. 2003. 736:D3.8.1-D3.8.6.

11. Shao C, Kim HY, Gong J, Ding B, Lee D-R and Park S-J. Fibermats of poly (vinyl alcohol) /silica composite via electrospinning. Materials Letters. 2003; 57:1579-1584. http:// dx.doi.org/10.1016/S0167-577X(02)01036-4

12. Peng $Z$ and Kong LX. Morphology of self assembled polyvinyl alcohol/silica nanocomposites studied with atomic force microscopy. Polymer Bulletin. 2007; 59:207-216. http://dx.doi. org/10.1007/s00289-007-0756-y

13. Kotoky T and Dolui SK. Synthesis and characterisation of polyvinyl alcohol/silica hybrid composites derived through the sol-gel method in aqueous medium: effect of acid content, silica content and viscosity of PVA on the dispersion characteristics of silica and the physical properties of the composites. Journal of Sol-Gel Science and Technology. 2004; 29(2):107-114. http:// dx.doi.org/10.1023/B:JSST.0000023011.15323.45

14. Koji N, Tomonora Y, Kenji I and Fumio S. Properties and structure of poly (vinyl alcohol)/silica composites. Journal of Applied Polymer Science. 1999; 74:133-138. http://dx.doi. org/10.1002/(SICI)1097-4628(19991003)74:1<133::AID-A PP16>3.0.CO;2-N

15. Guo R, Ma X, Hu C and Jiang Z. Novel PVA-silica nanocomposite membrane for evaporative dehydration of ethylene glycol aqueous solution. Polymer. 2007; 48:29392945. http://dx.doi.org/10.1016/j.polymer.2007.03.035

16. Bandyopadhyay A, De Sarkar M and Bhowmick A. Structureproperty relationship in sol-gel derived polymer/silica hybrid nanocomposites prepared at various pH. Journal of Materials Research. 2006; 41:5981-5993.

17. Bandyopadhyay A, De Sarkar M and Bhowmick A. Poly (vinyl alcohol)/silica hybrid nanocomposites by sol-gel technique: Synthesis and properties. Journal of Materials Science. 2005; 40:5233-5241. http://dx.doi.org/10.1007/ s10853-005-4417-y

18. Simon P, Ulrich R, Spiess H and Wiesner U. Block, Copolymerceramic hybrid materials from organically modified ceramic precursors. Chemistry of Materials. 2001; 13:3464-3486. http:// dx.doi.org/10.1021/cm0110674

19. Cerveau G, Corriu R and Lepeytre C. Organic-inorganic hybrid silica. Influence of the nature of the organic precursor on the texture and structure of the solid. Journal of Organometallic Chemistry. 1997; 548:99-103. http://dx.doi.org/10.1016/S0022328X(97)00257-X

20. Chevalier P, Corriu R, Moreau J and Man MWC. Chemistry of hybrid organic-inorganic: Access to silica materials through chemical selectivity. Journal of Sol-Gel Science and Technology. 1997, 8:603-607. http://dx.doi.org/10.1007/ BF02436908

21. Koski A, Yim K and Shivkumar S. Effect of molecular weight on fibrous PVA produced by electrospinning. Materials Letters. 2003, 58(3-4):493-497. http://dx.doi.org/10.1016/ S0167-577X(03)00532-9

22. Peng Z, Kong LX and Li SD. Non-isothermal crystallisation kinetics of self- assembled polyvinyl alcohol /silica nanocomposite. Polymer. 2005; 46(6):1949-1955. http://dx.doi. org/10.1016/j.polymer.2004.12.026 